\title{
Reaching the Hard to Reach and Excluded Groups-A Human Right Approach
}

\author{
Nabaraj Adhikari ${ }^{1 *}$ and Saraswati Adhikari ${ }^{2}$ \\ ${ }^{1}$ Master of Public Health, The Royal Tropical Institute (KIT), Netherlands \\ ${ }^{2}$ MPGD Scholar, Pokhara University Lekhanath Dhungepatan, Nepal
}

Submission: December 05, 2017; Published: January 11, 2018

*Corresponding author: Nabaraj Adhikari, Master of Public Health, The Royal Tropical Institute (KIT), Netherlands, Email: nobium.nab@gmail.com

\begin{abstract}
Nepal has made significant progress to reduce the HIV new infection and prevalence rate in general population as well in most at risk population. Having said that, certain groups such as labor migrants, female sex workers and people who inject drugs still face hindrance to exercise their right of access to service. Though the government of Nepal have signatory of various international human right convention and treaties the national policy on HIV and STI 2011 fails to address issues which are necessary to ensure people right to have a highest attainable standard of health, freedom from torture and other inhuman and degrading treatment and right not to be subjected to arbitrary arrest, detention or exile [1].
\end{abstract}

This paper identifies short failing to ensure access to HIV and AIDS and STIs services. These include inadequate funding, prevailing stigma and discrimination and legal hindrance which don't ensure the dignity of people living with HIV and sexual minority, which need proper attention from the ministry of health in policy level. To address aforementioned issues this paper identifies integration of HIV services with SRH services as one of the options. In addition to this creating enabling environment and provision of high-level multi-sectorial cross, broader steering committee would be the viable options. However, as a ministry of health has its limitation this paper suggested to take public health approach to address the human right issue of marginalized and excluded groups.

Keywords : HIV and AIDS; Human right approach; Policy analysis

\section{Introduction}

HIV epidemic in Nepal is highly concentered among the key population with an adult prevalence of $0.02 \%$ [2]. Around 39,249 people are estimated to be living with HIV in 2014 which is a decline from 40723 in 2013 [2,3]. However, HIV epidemic is concentered among people who inject drugs, male labor migrants and their spouses, female sex workers, transgender people and men who have sex with men. Nepal is a signatory to various international treaties and committed to providing access to service and information to the vulnerable group and people living with HIV. However, the government of Nepal fails to provide services and information for young people's living with HIV and labor migrants especially cross-border migrants between India and Nepal. Moreover, sexual minorities such as MSM, TG, FSW, and MSW couldn't able at access to service because of existing prejudice and discriminatory attitude prevailing at health system service point [3]. "The full realization of human rights and fundamental freedoms for all is an essential element in the global response to HIV epidemic in area of prevention treatment care and support"-Political declaration on HIV/AIDS; intensifying our efforts to eliminate HIV/AIDs adopted by the UN General Assembly on 10 June 2011(1)
Furthermore, still there are various laws and regulation which criminalized PLHIV and they become subject to arbitrary arrest, detention, and exile such as female sex workers and people who inject drugs which exacerbate the condition and make hurdle to those groups to access to services and information [4].

Though Nepal is a signatory of a major human right convention such as Universal declaration of human right, UN General assembly declaration of commitment on HIV/AIDS, and but still lack to address certain human right issues of sexual minority groups and marginalized groups. The HIV policy tried to incorporate human right as access to service but following issues need to be addressed to enrich right of neglected and marginalized groups;

A. Policy falls short to ensure access to HIV and AIDS and STIs services of some of the risk population such as cross-border migrants while they are in the destination country.

B. Policy abandoned the young people and children living with HIV need to access to service and provide enabling the environment to reduce stigma and discrimination.

C. The policy is inadequate to ensure internal funding 
mechanism to protect right of people to access the HIV and AIDS service.

D. The policy fails to ensure the dignity of people living with HIV and sexual minority group.

Undermining human right of minority groups and PLHIV aggravates disease condition and fuels the spread of HIV. To case in point discrimination and stigmatization of these groups' forces these groups to be hidden which inhibits the ability to reach for preventive activities and hiders their access to services [5]. So it important for MoHP to address these human right issues in its HIV and AIDS policy and this paper highlights some of these issues.

\section{Policy Issues and Options}

\section{Policy issues}

Migrants and mobile population and their spouses are one of the vulnerable groups for the HIV and AIDS [6]. In Nepal male labor migrants in far western and western higher are acting as a bridge between high concentrated epidemic to low-risk population, however, these groups are often unable to access the necessary HIV services in destination countries and even in Nepal [7]. For instance NCASC estimated that male labor migrants share the majority of HIV infection about 27 percent however exposure of current national HIV programs among migrants is very low about 1.9 and 15 percent of migrants were met with outreach educator another study shows that only 4 and 3 percent male migrants visited HIV testing center and met outreach or peer educator respectively [8]. The 61st world health assembly called up action its member states to protect the health of migrants to promote migrant-sensitive health system to promote equitable access to health services [9]. As the member states, Nepal needs to protect right of migrants to access to services and information by creating enabling environment through the provision of special provision which current national policy lacks to address.

Furthermore, the government of Nepal signatory of various human right treaties and convention but people living with HIV and their relative has faced various human right violations. HIV related human right violations such as stigma and discrimination, in particular discrimination against children affected by AIDS marginalized group, pervades into all aspects of lives creates a barrier to access to services. For instances, there are various laws and regulation which criminalized PLHIV and they become subject to arbitrary arrest, detention, and exile especially female sex workers and people who inject drugs [10]. Moreover, the drug control law against possession in Nepal means the possession of the small drug is a crime and the even possession of syringe may lead to imprisonment $[4,11]$. In addition, Nepalese laws are either ambiguous or silence on the issue of criminality of transactional sex that leaves space for the law enforcement agencies to have their own interpretation of these laws. These situations pose barriers to distribution of needle syringe to People Who Inject Drugs (PWID) as well as the distribution of condoms to sex workers [12]. On the other hand, there is policy lacks to address the funding challenge to ensure people right to a highest attainable standard of health. In national HIV policy, there is no alternative funding mechanism for HIV which can ensure people right to access to HIV services. The latest data on HIV spending shows only $3.5 \%$ HIV is contributed by government and majority of spending funded by donor agencies [13]. In addition, the policy doesn't address the health system capacity enhancement to make ensure availability accessibility and quality of services.

\section{Policy option}

Integration of HIV and SRH services: Sexual and reproductive ill-health and HIV also share root causes: lack of access to information and services; poverty; harmful gender norms and inequality; cultural norms; and social marginalization or criminalization of key populations [14]. Integrated SRHR and HIV programmes can be one policy option to strengthen and expand work to promote rights, address the root causes of vulnerability and reduce stigma and discrimination. Various examples around the world show integration of viable options to increase access to youths and marginalized groups. For instance in young people are best served through integrated programmes to prevent pregnancy, STIs, and HIV [14-17] (Figure 1).

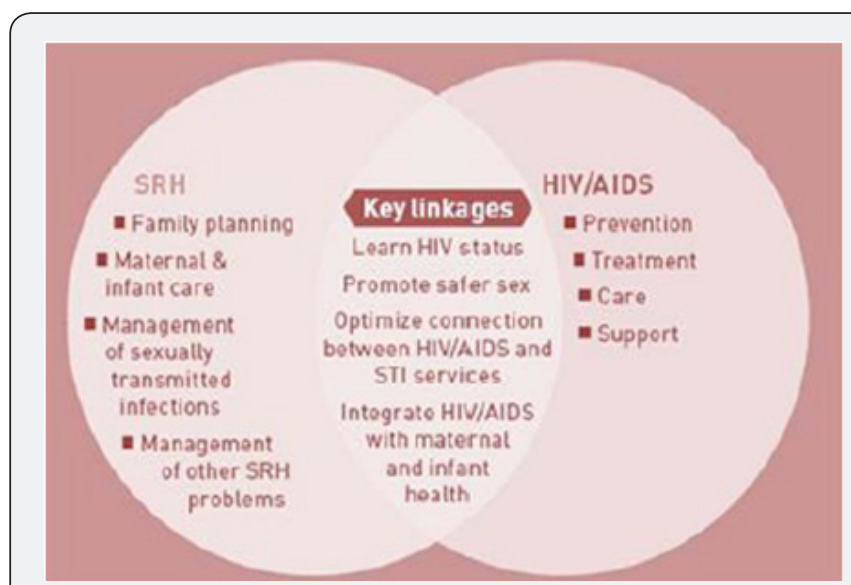

Figure 1: A framework for priority linkages between sexual and reproductive health and HIV [17].

One of the advantages of the integrated program is its meet people's SRH needs in a more holistic and positive way, rather than simply focusing on HIV infections, may be more attractive and less stigmatizing. Integrating family planning into HIV services may protect people with HIV from stigmatizing attitudes at a general clinic rather than attending a dedicated HIV service may expose people to more stigma than attending a broader, unmarked service. In addition, Joining up programmes can strengthen and broaden the coverage of activities aimed at understanding and changing harmful social, cultural and gender norms. They can also address the root causes of vulnerability. Activities include collective action, reinforcement of key messages and joint advocacy. However, integration might increase the workload for the staff with new responsibilities. This overburden of work may compromise the service quality [14]. 
Creating enabling environment through capacity building of minority groups, health service provider, and another stakeholder: To ensure universal access to HIV prevention, treatment, and care services, services should be nonjudgmental inclusive and responsive to need of marginalized groups [5]. A better understanding of sexual and sexuality diversity among heath care provider would help them to understand needs of the minority group from the human right perspective [14]. In addition, this will give minority group a sense of feeling that health care services are responsive, understand and respect their needs and identities. Furthermore increasing the capacity of minority groups will make them able to seek their right and services and helps them to recognize their competencies to stand for their issues not only access to service per sec. To exemplify capacity building policy of Los Angeles County Department of Health Service is one the effective and well-established policy which brings CBOs leader, health service provider and marginalized groups together and increase their knowledge and a range of skills [5]. This resulted in various CBOs and minority group able to utilize various forums to raise their issues and services provide also able to provide services according to minority group expectation. Nevertheless, an important challenge to create an enabling environment is making organization culture relevant and responsive to such changes to serve in their communities. In addition, it is quite changing to building trust between minority groups and other stakeholders.

Policy formulation on HIV and Cross broader migration with provision of high-level human right monitoring committee: International labor migrants have the same human rights as everyone else [18] and its government responsibility to ensure their right to health services. In Nepal migrant are vulnerable at each stage of the migration process requires concerted actions from governments and other stakeholders in both origin and destination countries. Hence there is an urgent need of policy which addresses the human right of cross broader migrants. This policy should include the provision of a high level human right monitoring committee to safeguard the human right of cross broader migrants as well other excluded groups. This high-level commission would help to link people the PLHIV to the HIV services in destination countries. For instance, government of Nepal can learn from Care International steering committee success provided a diverse range of HIV and AIDS services to cross-border migrants in India, Nepal and Bangladesh [19]. Such committee will facilitate the environment to come multiple stakeholders come together to ensure right to access services of origin but also in the county of destination. The Sir Lank government offers a good example where Ministry of Health is leading the multi-sectoral team to address the gap for migrants' health [20]. Having said that there a challenge to make the harmony and good collaboration to work together for health and wellbeing of migrant especially targeting HIV and AIDS.

Changing basic laws and policies: decriminalized sex work and IDUs: Various examples around the world show that decriminalization for sex workers in jurisdictions as a legitimate profession have increased the SW access to HIV and SRH services [21]. For instance in Zealand and New South Wales decriminalization helps to maintain a very low level of STIs and HIV transmission among sex worker is almost nonexistence. The advantage of legal recognition of sex work as occupation help them claim benefits, form or join unions and other workrelated insurance. On the other hand, people argues that decriminalization of small amount illicit drugs will increase the HIV transmission among IDUs, which is not the case. To case in point, Portugal decriminalization statute helps to increase funding for drug treatment centers and introduced harm reduction services to the dependent drug [11]. After enforcement, this law, the number of dependent drug users seeking treatment increased threefold and drug-related harms have significantly declined, including the incidence of HIV. Similarly, examples from Australia and Italy show the positive effect to increase access among drug users [11]. However, there a huge difference in social cultural, religious, education and economic context of Nepal compare to aforementioned countries. Without addressing other social determinates it is difficult to push forward the agenda and implement it in long run.

\section{Conclusion}

Though there are various ways to tackle human right issues of access to services of marginalized groups and excluded groups such as labor migrants, sex workers, and transgender. However, some of them are not in fully in the dimension of Ministry of Health such as legal reforms. In addition, some issues need multi- sectorial cooperation and collaboration which MOHP alone cannot ensure. For this reason, I would suggest honorable minister to consider public health approach of integration of HIV and SRH services which would able to address issues of migrants, sex workers, young people and other minority groups.

\section{Recommendations}

To make ensure human right to access the HIV and AIDS services of the marginalized group through integration with SRH and following recommendation were suggest operationalizing this integration policy.

A. Conduct the operational research to measure the effectiveness and workability of the integration in Nepalese context.

B. Development of high level "Joint task group on integration" involving stakeholders such as Family Health Division, a representative from a marginalized group, donor agencies, and UN agencies working on HIV and SRH to suggest and develop a guideline for integration.

C. Conditioning donor workshop to seek support and commitment in the line with MoHP policy for integration.

D. Strengthening the health services with human resources and technical equipment to ensure the quality of the integrated services. 
E. Develop collaboration between public and private health services provider and civil society organization who are working with hard to reach groups.

\section{References}

1. (2006) UNAIDS: International Guidelines on HIV/AIDS and Human Rights 2006 Consolidated Version. Geneva United Nations High Commissioner for Human Rights, The Joint United Nations Programme on HIV/AIDS.

2. (2015) Factsheet 1: HIV Epidemic Update of Nepal, December 2014 [Internet]. Ministry of Health and Population National Centre for AIDS and STD Control.

3. (2015) Ministry of Health and Population, National Centre for AIDS and STD Control. Country Progress Report Nepal Kathmandu Ministry of Health and Population National Centre for AIDS and STD Control.

4. (2010) National Association of PLHA in Nepal $(\mathrm{NAP}+\mathrm{N})$, The Global Network of People Living with HIV (GNP+), (APN+) APNoPLwHA Human rights count, Documentation of hiv-related human rights violation against people living with HIV Nepal Kathmandu National Association of PLHA in Nepal $(\mathrm{NAP}+\mathrm{N}) 2010$

5. (2005) CDC: Health CoAaC. HIV prevention capacity building: A framework for strengthening and sustaining hiv prevention programs.

6. (2011) Nepal Migration Year Book, Nepal Instittute of Development Studies(NIDS), Nepal.

7. Poudel KC, Jimba M, Okumura J, Sharma M, Poudel Tandukar K, et al. (2004) Migration in far western Nepal: a time bomb for a future HIV/ AIDS epidemic? Trop Doct 34(1): 30-31.

8. (2008) Integrated Biological and Behavioral Surveillance Survey among Male Labor Migrants in 11 Districts in Western and Mid to FarWestern Regions of Nepal Round II Kathmandu NCASC, FHI, USA.

9. WHO (2008) Sixty-First World Health Assembly: Resolution and Decisions Geneva World Health Organization, Geneva, Switzerland.

10. Sanghera J, Kapur MR (2000) Trafficking in Nepal: An Assessment of Laws and Policies for the Prevention and Control of Trafficking in Nepal. The Asia Foundation and Population Council.

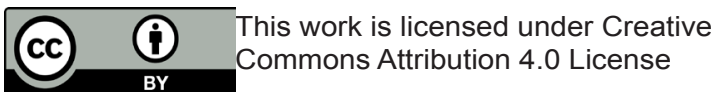

11. Jessica Chiu SB (2011) Punitive drug law and the risk environment for injecting drug users: Understanding the connections. Working paper prepared for the Third Meeting of the Technical Advisory Group of the Global Commission on HIV and the Law, Pp. 7-9.

12.(2014) UNAIDS: National Commitments and Policies Instrument (NCPI), Nepal.

13. (2013) NCASC: The Nepal HIV Investment Plan 2014-2016 Ministry of Health and Population, National Centre for AIDS and STD Control Teku, Nepal.

14. (2010) Alliance IHA: Integration of HIV and sexual and reproductive health and rights: Good Practice Guide International HIV/AIDS Alliance.

15. (2013) Alliance IHA: Integrating HIV and sexual and reproductive health and rights: reaching and engaging the young people most affected by HIV. Hove, United Kingdom.

16. Sultana MM, Samuels F, Devkota P (2014) An integrated approach to address mobile people's vulnerability to HIV and migration: EMPHASIS experiences in a nutshell. Ref World.

17. (2010) UNAIDS, Sexual and Reproductive Health (SRH) services with HIV interventions in practice. UNFPA.

18. (2008) Policy brief HIV and international labour migration, UNAIDS

19. Walker D, Bohidar N, Devkota P (2014) Migration, health and dignity in South Asia: Lessons from the EMPHASIS project on migration, women's empowerment and HIV in Bangladesh, India, and Nepal.

20. Calderon J, Rijks B, Agunias DR (2012) Asian labor migrants, and health: Exploring policy routes. International Organization for Migration (IOM) and Migration Policy Institute, Bangkok and Washington, USA

21. Godwin J (2012) Sex work and the law in Asia and the Pacific: Laws, HIV, and human rights in the context of sex work. Thailand: UNDP, UNAIDS, UNFPA.

\section{Your next submission with Juniper Publishers} will reach you the below assets

- Quality Editorial service

- Swift Peer Review

- Reprints availability

- E-prints Service

- Manuscript Podcast for convenient understanding

- Global attainment for your research

- Manuscript accessibility in different formats

( Pdf, E-pub, Full Text, Audio)

- Unceasing customer service

Track the below URL for one-step submission https://juniperpublishers.com/online-submission.php 